*Doutor em Direito pela Pontifícia Universidade Católica de São Paulo

Professor do Programa de Pósgraduação em Direito da Universidade de Marília

E-mail: jbvita@gmail.com

**Doutor em Direito e Mestre em Direito Econômico pela Universidade Federal da Paraíba Professor do Programa de Pósgraduação em Direito da Universidade de Marília

E-mail: bbastos.adv@gmail.com

***Mestranda pelo Programa de Pós-Graduação em Direito da Universidade de Marília E-mail: anacpcadv@gmail.com

\section{ASPECTOS JURÍDICOS RELACIONADOS À REDE SOCIAL ONLYFANS: UMA ABORDAGEM NA PERSPECTIVA DAS RELAÇÕES DE CONSUMO}

\author{
LEGAL ASPECTS RELATED TO THE ONLYFANS \\ SOCIAL MEDIA: AN APPROACH FROM THE \\ PERSPECTIVE OF CONSUMER RELATIONS
}

\author{
Jonathan Barros Vita* \\ Bruno Bastos de Oliveira** \\ Ana Carolina Pazin Costa***
}

Como citar: VITA, Jonathan Barros; DE OLIVEIRA, Bruno Bastos; COSTA, Ana Carolina Pazin. Aspectos jurídicos relacionados à rede social onlyfans: uma abordagem na perspectiva das relações de consumo. Scientia luris, Londrina, v. 25, n. 3, p. 141158, nov. 2021. DOI: 10.5433/21788189.2021v25n3p141. ISSN: 2178-8189.

Resumo: O artigo tem como objetivo principal analisar, sob um prisma jurídico, a rede social OnlyFans, em especial na perspectiva do Código de Defesa do Consumidor. Para tanto, inicialmente, trata a OnlyFans no âmbito da legislação de proteção do consumidor, definindo os elementos da relação de consumo, como o consumidor, o fornecedor e o serviço, bem como pontuando outros aspectos como a intervenção do Estado no mercado de consumo. Analisa ainda as cláusulas contratuais abusivas e os possíveis reflexos jurídicos dos termos de uso da rede social à luz do Código de Defesa do Consumidor. Utilizando-se do método dedutivo, mediante a pesquisa, leitura e análise documental e bibliográfica, conclui-se pela incidência da relação consumerista na perspectiva da rede social em destaque, observando-se a necessidade de adequação das cláusulas contratuais abusivas da plataforma frente ao ordenamento jurídico brasileiro.

Palavras-chave: OnlyFans. Rede social. Direito do consumidor. Cláusulas abusivas.

Abstract: This paper analyzes, under a legal perspective, the social network OnlyFans, especially from the perspective of the Consumer Protection Code. To this end, it initially deals with OnlyFans within the scope of consumer protection legislation, defining the elements of the consumer relationship, such as the 
consumer, the supplier and the service, as well as pointing out other aspects such as state intervention in the consumer market. It also analyzes the unfair contractual terms and the possible legal consequences of the terms of use of the social network considering the Brazilian Consumer Protection Code. Using the deductive method, with research, reading and analysis of documents and related literature, this study concludes that the consumer relationship from the perspective of the social network in question should observe to Brazilian legal norms in face of the Brazilian legal system.

Keywords: OnlyFans. Social media. Consumer law. Abusive clauses. 


\section{INTRODUÇÃO}

A presente pesquisa teve como objeto a análise jurídica da rede social OnlyFans na perspectiva do Código de Defesa do Consumidor (Lei $\mathrm{n}^{\circ}$ 8.078, de 11 de setembro de 1990), especialmente diante das constantes repercussões jurídicas geradas na era do consumidor digital. O Código de Defesa do Consumidor conceitua os tipos de consumidor, de fornecedor e de serviço abrangidos pela relação de consumo. Por sua vez, a rede social OnlyFans estabelece que a plataforma fornecedora de serviços é composta por Usuário Criador e Usuário Fã.

Os objetivos do presente artigo se restringiram a abordar a rede social no que tange às cláusulas contratuais abusivas e os reflexos jurídicos no Direito do Consumidor. Assim, com a intenção de atingir objetivos gerais e específicos, o presente artigo foi dividido em duas seções.

Na primeira seção analisa-se a rede social OnlyFans no âmbito da legislação de proteção ao consumidor, especificando os elementos da relação de consumo, além de aludir, brevemente, a outras particularidades como a intervenção do Estado no mercado de consumo.

$\mathrm{Na}$ segunda e última seção, onde reside o problema central da presente pesquisa, são examinados as cláusulas contratuais abusivas e os possíveis reflexos jurídicos da rede social à luz do Código de Defesa do Consumidor, citando, até mesmo, o caso da atriz da Disney Channel, a Bella Thorne.

Pretendeu-se, assim, transmitir para o artigo significativas considerações jurídicas sobre a OnlyFans no que corresponde à relação de consumo para, com isso, fomentar reflexões jurídicas quanto à rede social, as cláusulas contratuais abusivas e as possíveis consequências jurídicas dos termos de uso à luz do Código do Consumidor, estimando um melhor funcionamento da plataforma no ordenamento jurídico brasileiro, além de oferecer maior informação ao consumidor de serviço de conteúdo virtual OnlyFans.

\section{A REDE SOCIAL ONLYFANS NO ÂMBITO DA LEGISLAÇÃO DE PROTEÇÃO AO CONSUMIDOR}

A Lei $n^{\circ} 8.078 / 1990$ possui a incumbência de reequilibrar as forças dos sujeitos da relação consumerista, minimizar a vulnerabilidade do consumidor e limitar as práticas nocivas de mercado (SILVESTRINI; GERAIGE NETO; VILELA, 2019). Por isso, faz-se oportuno analisar a rede social OnlyFans no âmbito da legislação de proteção ao consumidor, especificando os elementos da relação consumerista como o consumidor, o fornecedor e o serviço, além de elucidar outros aspectos.

No que diz respeito aos elementos da relação de consumo, dividem-se em elementos subjetivos e objetivos. Os primeiros são o consumidor e o fornecedor, já os objetivos são o produto e o serviço. In casu, busca-se detalhar apenas os elementos aplicados na plataforma OnlyFans. 


\subsection{A IDENTIFICAÇão do CONSUMidor DENTRo da PLATAForma OnLyFans}

Inicialmente, entende-se consumidor como elemento subjetivo da relação de consumo. A Lei $\mathrm{n}^{\mathrm{o}}$ 8.078/1990 apresenta quatro sentidos de consumidor, sendo o primeiro o consumidor stricto sensu ou standard e os outros três consumidores equiparados, respectivamente, a saber:

Consumidor stricto sensu ou standard é toda pessoa física ou jurídica que adquire ou utiliza produto ou serviço como destinatário final, consoante o artigo $2^{\mathrm{ol}}$ da Lei. Atentando-se ao enquadramento inicial, o consumidor pode ser, pelo texto expresso, uma pessoa natural ou jurídica, sem qualquer distinção (TARTUCE; NEVES, 2020).

Por sua vez, equipara-se a consumidor a coletividade de pessoas, ainda que indetermináveis, que haja intervindo nas relações de consumo, conforme o parágrafo único ${ }^{2}$ do citado artigo. Tratase, no caso, de consumidor em sentido coletivo. No que se refere à responsabilidade pelo fato do serviço, equiparam-se aos consumidores todas as vítimas do evento, sendo denominado de consumidor bystander, segundo o artigo $17^{3}$ da Lei.

Bem assim, quanto às práticas comerciais e à proteção contratual, equiparam-se aos consumidores todas as pessoas determináveis ou não, expostas às práticas nele previstas, fulcro no artigo $29^{4}$ da Lei. É o chamado consumidor potencial ou virtual.

Posto isto, percebe-se que o consumidor stricto sensu ou standard refere-se tanto a pessoa física quanto a pessoa jurídica que adquire ou utiliza produto ou serviço como destinatário final. Neste artigo interpreta-se destinatário final em harmonia com a Teoria Finalista (Subjetiva) e, também, de forma relativizada, em atenção à jurisprudência do Superior Tribunal de Justiça, entendo-se como Teoria Finalista Aprofundada ou Mitigada. Isso porque, se, de um lado, o Superior Tribunal de Justiça empregou o conceito finalista de consumidor, de outro, tem assegurado a necessidade de relativizá-lo para acolher, excepcionalmente, como consumidor, a pessoa física ou jurídica profissional, que adquire produto ou serviço para incrementá-lo em sua atividade, desde que demonstrada, in concreto, sua vulnerabilidade técnica ${ }^{5}$, jurídica ou econômica (ANDRADE; MASSON; ANDRADE, 2018).

A partir disso, o destinatário final pode ser fático e econômico. O primeiro compreende o consumidor como o último elemento da cadeia de consumo, ou seja, depois dele não há ninguém na transmissão do produto ou do serviço, já o segundo refere-se ao consumidor que não utiliza o produto ou o serviço para o lucro, repasse ou transmissão onerosa (TARTUCE; NEVES, 2020).

1 Art. $2^{\circ}$ Consumidor é toda pessoa física ou jurídica que adquire ou utiliza produto ou serviço como destinatário final. (BRASIL, 1990).

2 Parágrafo único. Equipara-se a consumidor a coletividade de pessoas, ainda que indetermináveis, que haja intervindo nas relações de consumo. (BRASIL, 1990).

3 Art. 17. Para os efeitos desta Seção, equiparam-se aos consumidores todas as vítimas do evento.

4 Art. 29. Para os fins deste Capítulo e do seguinte, equiparam-se aos consumidores todas as pessoas determináveis ou não, expostas às práticas nele previstas. (BRASIL, 1990).

5 Vulnerabilidade técnica: resultado do fato de o consumidor não ter conhecimento acerca do produto/serviço que está em circulação no mercado, estando, assim, subordinado aos ditames da política do mercado. Esse tipo de vulnerabilidade relaciona-se à falta ou inexatidão de informações prestadas ao consumidor. $\mathrm{O}$ fornecedor monopoliza o conhecimento e o controle dos mecanismos da cadeia produtiva, por isso, o consumidor não tem como avaliar o que está comprando ou o serviço que está contratando. (ANDRADE, 2020, p. 65). 
Assim, o mero Usuário da rede social OnlyFans, aquele que só usufrui do conteúdo gerado pelo Usuário Criador, através de mensalidade, deve ser visto como consumidor stricto sensu ou standard, pois concerne à pessoa física que adquire ou utiliza o serviço de fotos, vídeos e/ou áudios da plataforma para fim pessoal, sem inseri-lo na atividade profissional com finalidade lucrativa, sendo ele destinatário fático e econômico, de acordo com a Teoria Finalista, portanto. Tal como o denominado Fã.

Em contrapartida, o Usuário Criador, aquele que cria e/ou gera conteúdo (fotos, vídeos e áudios) à rede social para que outros usuários vejam suas publicações, também pode ser analisado como consumidor stricto sensu, quando está na posição de consumidor de conteúdo de outros Usuários Criadores, porém, este consumidor deve demonstrar sua vulnerabilidade no caso concreto, já que, apesar de se reportar à pessoa física que utiliza o serviço de conteúdo digital, tem viés para a atividade profissional, uma vez que o Criador, além de ser um mero usuário de conteúdo de terceiros, pode auferir lucro com o conteúdo criado para os seus Fãs. Logo, ajusta-se, em tese, à Teoria Finalista Mitigada.

Ressalta-se aqui que, de acordo com os Termo de $\mathrm{Uso}^{6}$ da plataforma, só pode ser consumidor-usuário da rede social, seja na qualidade de Fã ou de Criador, aquele que possuir 18 (dezoito) anos ou mais.

Na perspectiva do consumidor equiparado, o Usuário da mídia social OnlyFans, seja Fã ou Criador, pode ser enquadrado como vítima do acidente de consumo (bystander), porque basta a plataforma apresentar um serviço defeituoso para o Usuário (consumidor) acionar as normas protetivas que regulam a responsabilidade civil consumerista.

Quanto ao consumidor em sentido coletivo, prescinde de ato de consumo para veicular a relação entre consumidor e fornecedor, uma vez que basta integrar a coletividade de pessoas, determináveis ou não, para sofrer os efeitos colaterais danosos derivados do serviço de conteúdo. Melhor dizendo, todas as pessoas, ainda que indetermináveis, que não usuárias (aderentes) da plataforma, podem ser expostas à conduta da empresa fornecedora de serviço de conteúdo digital. Assim sabendo, consagra-se o Estado interventivo para uma espécie de tutela coletiva preventiva para proteger os interesses dos consumidores (usuários ou não).

Em relação, por último, ao consumidor virtual ou potencial, é suficiente que o consumidor esteja exposto às práticas contratuais ou comerciais abusivas, ou seja, desnecessário identificar quais as pessoas estão de fato expostas. Neste caso, a tendência da normatização, isto é, intervenção do Estado na relação de consumo, é viabilizar um controle preventivo e abstrato das práticas abusivas, protegendo o consumidor vulnerável seja ou não usuário da rede social, inibindo as ofertas ou práticas abusivas que desequilibrem a relação consumerista (ANDRADE; MASSON; ANDRADE, 2018).

No que está relacionado ao Estado interventivo, a regulação do mercado, enquanto interesse da atividade do Estado, surge como um conjunto de medidas, pelas quais o Estado intervém nas liberdades privadas de modo a controlar e influenciar o comportamento dos agentes econômicos,

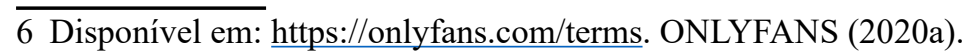


com o intuito de evitar danos (falhas) no desenvolvimento econômico-social, conduzindo, assim, a atividade privada a buscar o bem-estar social. Tal regulação tende a proporcionar o equilíbrio do mercado consumerista (ROSSIGNOLI; ALMEIDA, 2018).

De mais a mais, é sabido que a era digital veio alterar por completo o comportamento dos consumidores tradicionais, a maneira como estes se relacionam com as empresas fornecedoras de serviço, como se comportam online e a forma como adquirem produtos ou serviços (LAHER, 2019). Nesse raciocínio:

Consumo é ao mesmo tempo um processo social que diz respeito a múltiplas formas de provisão de bens e serviços e a diferentes formas de acesso a esses mesmos bens e serviços; um mecanismo social percebido pelas ciências sociais como produtor de sentido e de identidades, independentemente da aquisição de um bem; uma estratégia utilizada no cotidiano pelos mais diferentes grupos sociais para definir diversas situações em termos de direitos, estilo de vida e identidades; e uma categoria central na definição de sociedade contemporânea. (MONTARDO; ARAÚJO, 2013, p. 477).

Outrossim, há de se considerar os fatores sociais, culturais, pessoais e psicológicos que influenciam o consumidor contemporâneo a consumir determinados serviços virtuais, inclusive de natureza erótica.

$\mathrm{Na}$ trilha da teoria da sociedade de consumo, por fim, já se disse, por exemplo, que o mercado representa uma falência do viés regulamentador estatal e encontra terreno propício ao seu desenvolvimento, justamente pelos elementos nesse universo de consumidores, como seres desejantes sempre em busca do novo. Aliás, como tudo é interpretado como mercadoria ou produto, Bauman resgata a noção de que o mercado revivesceu a lenda do Rei Midas: o que ele toca, não importa o que seja, resulta em mercadoria de consumo, inclusive as coisas que tentam escapar a esse controle e até os meios e formas utilizados em suas tentativas de escape (BALDUÍNO JÚNIOR; SANTIAGO, 2021). À vista disso, o usuário da OnlyFans pode ser classificado como consumidor em sentido estrito ou equiparado, a depender da situação analisada no caso concreto.

\subsection{A Figura do Fornecedor NA PLATAFORMA ONLYFANS}

Igualmente ao consumidor, o fornecedor também integra a relação de consumo como elemento subjetivo. O vocábulo "fornecedor" alberga tanto o fornecedor de produtos em sentido estrito como o prestador de serviços, sendo tratado em sentido amplo no artigo $3^{07}$ do Código de Defesa do Consumidor. Nesse aspecto, a doutrina ensina que:

Os fornecedores ou prestadores podem ser pessoas jurídicas de Direito Público ou

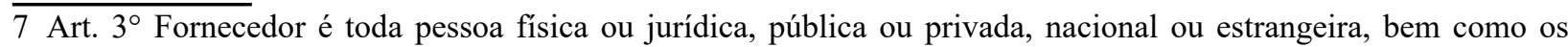
entes despersonalizados, que desenvolvem atividade de produção, montagem, criação, construção, transformação, importação, exportação, distribuição ou comercialização de produtos ou prestação de serviços. (BRASIL, 1990).
} 
de Direito Privado. [...] Entre as últimas, os grandes fornecedores e prestadores são empresas privadas, inclusive com atuação em vários países (empresas multi ou transnacionais). Nesse contexto, a dicção legal estabelece que o fornecedor pode ser uma pessoa nacional ou estrangeira, sendo irrelevante qualquer tipo de limitação. (TARTUCE; NEVES, 2020, p. 64).

Além disso, Flávio Tartuce e Daniel Amorim Assumpção Neves pontuam que, segundo Antônio Junqueira de Azevedo, o que interessa mesmo na caracterização do fornecedor ou prestador é o fato de ele desenvolver uma atividade que vem a ser a soma de atos coordenados para uma finalidade específica, bem como o fato de a atividade possuir habitualidade, à luz dos ensinamentos de José Fernando Simão.

Extrai-se disso que o Código Consumerista elencou um rol exemplificativo (numerus apertus) de atividades que podem ser desenvolvidas pelo fornecedor e/ou prestador de serviços, todavia, tal atividade deve ser profissional, com o objetivo de auferir lucro direto ou vantagens indiretas (TARTUCE; NEVES, 2020). Salienta-se, ainda, que apesar de a atividade profissional se caracterizar pela reiteração de condutas (habitualidade) conjugada a especialidade, com a finalidade de obter vantagem econômica, há que se ponderar que tal atividade independe de finalidade lucrativa, isto é, suficiente que o fornecedor anseie por vantagem econômica, seja através de contraprestação pecuniária, remuneração ou outra espécie (ANDRADE; MASSON; ANDRADE, 2018).

Assim sendo, identifica-se a empresa da rede social OnlyFans como fornecedora de serviços - diga-se: conteúdo virtual de fotos, vídeos e/ou áudios, inclusive com mensagens/textos - com a finalidade de obter vantagem econômica mediante pagamento mensal para acesso ao conteúdo publicado, porém tal plataforma utiliza-se de um intermediário na relação, qual seja, o Usuário Criador, fazendo com que este crie conteúdo para os Usuários Fãs e, consequentemente, também obtenha lucro com a transferência de conteúdo, mas, por usar determinado intermediador, paga-se, além de a remuneração mensal, um percentual no que toca à vantagem econômica obtida com a "doação" dos Fãs. Em outras palavras, a empresa Fenix International Limited- FIL ${ }^{8}$ é fornecedora de serviço, uma vez que fornece aos usuários aderentes da rede social conteúdo de fotos, vídeos e/ou áudios, mediante contraprestação pecuniária mensal. Não obstante, ponderase que o Usuário Criador ${ }^{9}$ pode ser analisado como fornecedor de conteúdo quando utiliza a plataforma para divulgar o seu serviço de conteúdo, auferindo lucro com o pagamento mensal de

\section{fãs, gorjetas e até comissão.}

Por conseguinte, em tese, a responsabilidade pelo fornecimento de conteúdo com vício do serviço poderia recair tanto em face da OnlyFans quanto do Usuário Criador, a depender do exame do caso concreto, conforme será explicado mais adiante.

Por fim, verifica-se que a plataforma OnlyFans traduz-se em fornecedora de serviço de conteúdo (virtual) em conformidade com o preceituado no Código de Defesa do Consumidor.

8 OnlyFans is operated by Fenix International Limited. ONLYFANS (2020a).

9 No México, um grupo de detentos criou um perfil na plataforma digital OnlyFans e começaram a vender conteúdo erótico mediante assinatura, tudo feito diretamente de dentro do presídio em que se encontram reclusos. (GANEM, 2021). 


\subsection{Serviço na perspectiva da Plataforma Only Fans}

O serviço concerne ao elemento objetivo da relação de consumo assim como o produto. Por seu turno, serviço traduz-se em qualquer atividade fornecida no mercado de consumo, mediante remuneração (em sentido amplo). A definição jurídica seja de produto seja de serviço encontra-se no Código de Defesa do Consumidor, nos parágrafos $1^{010}$ e $2^{011}$ do artigo $3^{\circ}$. Salienta-se que a relação contida no parágrafo $2^{\circ}$ é meramente exemplificativa, quer dizer, além das atividades elencadas, é possível outra atividade mesmo que não prevista no diploma legal, respeitada a exceção.

No que se refere ao serviço, ainda, a atividade oferecida no mercado de consumo pode estar ligada à remuneração direta ou indireta. Na primeira o pagamento é efetuado pelo consumidor ao fornecedor diretamente, já na segunda a remuneração é embutida e outros custos, diferente do produto que prescinde de remuneração como pressuposto à atividade (ANDRADE; MASSON; ANDRADE, 2018).

No caso da OnlyFans, portanto, tem-se que a empresa oferece no mercado de consumo serviço de conteúdo digital de fotos, vídeos e/ou áudios com ou sem mensagens ou textos, inclusive de natureza erótica, onde recebe remuneração mensal direta e indiretamente, uma vez que o usuário paga um valor mensal para usufruir do conteúdo exclusivo da rede social, mas, ao mesmo tempo, paga para aderir ao conteúdo do Usuário Criador como Fã, podendo oferecer gorjeta ao criador, quando entender necessário.

\section{AS CLÁUSULAS CONTRATUAIS ABUSIVAS E OS REFLEXOS JURÍDICOS DA REDE SOCIAL À LUZ DO CÓDIGO DE DEFESA DO CONSUMIDOR}

A defesa do consumidor se consolida a partir da proteção da dignidade humana que se encontra em situação de particular vulnerabilidade, visando concretizar a obediência aos seus valores existenciais, isso porque uma das circunstâncias que acarreta essa vulnerabilidade dos consumidores é a chamada de assimetria informacional (espécie do gênero falhas de mercado) que é um desequilíbrio entre as partes seja quanto ao teor ou quanto à quantidade de informações nas relações econômicas (CZELUSNIAK, 2018), tal como ocorre nos contratos de adesão no mercado de consumo virtual. Em razão disso, o Estado intervém na relação de consumo, através da Lei $\mathrm{n}^{\circ}$ 8.078/1990, para relativizar as falhas de mercado - os danos derivados das informações assimétricas -, criando, por exemplo, limites às práticas ou cláusulas contratuais abusivas.

A propósito, são as falhas de mercado, tal como as assimetrias informacionais, que conectam o Estado da economia, buscando formas alternativas de reparar defeitos comportamentais

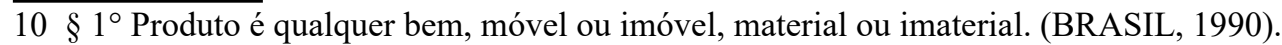

$11 \S 2^{\circ}$ Serviço é qualquer atividade fornecida no mercado de consumo, mediante remuneração, inclusive as de natureza bancária, financeira, de crédito e securitária, salvo as decorrentes das relações de caráter trabalhista. (BRASIL, 1990). 
que afastam os mercados de um funcionamento ótimo e socialmente almejado, com grande tendência auto predatória, particularmente no que tange à relação jurídica determinada pela vulnerabilidade de uma das partes (consumidor, no caso) e forte índice de desequilíbrio econômico (NASCIMENTO, 2015).

Assim, é válido mencionar, nesta seção, algumas cláusulas contratuais abusivas previstas nos Termos de Uso/Serviço ${ }^{12}$ da plataforma em questão, bem como os respectivos reflexos jurídicos à luz do Código de Defesa do Consumidor. Por certo, sem a intenção de esgotar as espécies de cláusulas abusivas previstas no Código do Consumidor, é importante abordar as cláusulas mais relevantes diante dos Termos de Serviço da OnlyFrans.

Antes de outras ponderações, sugere-se ao leitor, com a finalidade de suplementar o conhecimento sobre a temática, o artigo "OnlyFans: Considerações sobre a rede social e a Análise Econômica do Direito em relação ao Código de Defesa do Consumidor", de elaboração dos mesmos autores do presente artigo, que versa sobre os termos de serviço da plataforma, tratando a Economic Analysis of Law à luz do Direito do Consumidor.

No que corresponde às cláusulas abusivas, o artigo $6^{\circ}$, inciso $\mathrm{IV}^{13}$, da Lei $\mathrm{n}^{\circ}$ 8.078/1990 dispõe que entre os direitos básicos do consumidor está a proteção contra práticas e cláusulas abusivas ou impostas no fornecimento de serviços. Ademais, a Lei enuncia um rol exemplificativo (numerus apertus) de cláusulas contratuais abusivas no artigo $51^{14}$. Assim, infere-se do inciso $\mathrm{I}^{15}$ que é nula de pleno direito a cláusula de não indenizar, isto é, que exonera ou atenua o fornecedor de qualquer responsabilidade por vício e/ou fato do serviço, assim como a de renúncia ou disposição de direitos.

Entretanto, ao analisar os Termos de Serviço ${ }^{16}$ da rede social OnlyFans nota-se que a empresa britânica mantém cláusulas de isenção e limitação de responsabilidade. Em síntese, há cláusulas nos seguintes sentidos: (I) que a FIL não é responsável perante terceiros pelo conteúdo ou precisão de conteúdo postado por qualquer usuário da rede social (11.5 $\left.{ }^{17}\right)$; (II) que o usuário da rede social reconhece e concorda $\left(16.1^{18}\right)$ : que todos os serviços e recursos da plataforma são fornecidos sem garantias de qualquer espécie, expressas ou implícitas; que a FIL se isenta de todas e quaisquer garantias com relação a OnlyFans e todos os serviços e recursos, bem como não garante a precisão, utilidade, integridade ou confiabilidade da OnlyFans e se isenta de qualquer responsabilidade decorrente de qualquer confiança depositada no conteúdo por qualquer usuário da plataforma; mais, que a FIL não garante que a OnlyFans e todos os seus serviços e funcionalidades

12 ONLYFANS (2020a).

13 Art. $6^{\circ}$ São direitos básicos do consumidor: [...] IV - a proteção contra a publicidade enganosa e abusiva, métodos comerciais coercitivos ou desleais, bem como contra práticas e cláusulas abusivas ou impostas no fornecimento de produtos e serviços. (BRASIL, 1990).

14 Art. 51. São nulas de pleno direito, entre outras, as cláusulas contratuais relativas ao fornecimento de produtos e serviços que: [...] (BRASIL, 1990).

15 I - impossibilitem, exonerem ou atenuem a responsabilidade do fornecedor por vícios de qualquer natureza dos produtos e serviços ou impliquem renúncia ou disposição de direitos. Nas relações de consumo entre o fornecedor e o consumidor pessoa jurídica, a indenização poderá ser imitada, em situações justificáveis.

16 ONLYFANS (2020b).

17 11.5 FIL is not responsible or liable to any third party for the content or accuracy of any User Content posted by you or any other user of the Website. Disponivel em: https://koboguide.com/onlyfans-refund-tips/)

1816.1 By using OnlyFans, you acknowledge and agree as follows:[...] Disponível em: https://koboguide.com/ onlyfans-refund-tips/. 
estarão disponíveis em qualquer momento ou que todos os seus serviços e funcionalidades serão seguros, ininterruptos e livres de erros; que a FIL não será responsável por qualquer perda ou dano causado por um ataque de vírus ou outro material tecnologicamente prejudicial que possa infectar programas de computador, dados ou outro devido ao uso do site ou serviços obtidos por meio deste para o download de conteúdo postado nele ou vinculado (16.1.1 ${ }^{19}$ ); que em nenhum caso a responsabilidade da FIL é total para com o usuário (ou outros) decorrente do uso ou qualquer dos serviços da OnlyFans ou excederá 100 (cem) libras esterlinas $\left(16.1 .4^{20}\right)$; e (III) que por algumas jurisdições não permitirem a exclusão da responsabilidade por danos - em sentido amplo - a responsabilidade será limitada ao máximo permitido por lei ou, se não houver valor, a 100 (cem) libras esterlinas $\left(16.2^{21}\right)$.

Em que pese a previsão de tais cláusulas nos Termos de Uso, à luz do ordenamento jurídico brasileiro são nulas de pleno direito as cláusulas que exonerem ou atenuem a responsabilidade do fornecedor, pois este é responsável pelo serviço fornecido no mercado de consumo, conforme os artigos $14^{22}$ e $20^{23}$ do Código de Defesa do Consumidor. Todavia, em casos excepcionais é possível limitar a responsabilidade do fornecedor frente ao consumidor, desde que a situação seja justificável no caso concreto diante de uma análise judicial.

Aliás, a responsabilidade civil do fornecedor de serviço é, em regra, objetiva, ou seja, independe de culpa, estando fundamenta no risco da atividade. No mais, a responsabilidade pelo fato do serviço deriva dos danos causados aos consumidores, ora Usuários, por defeitos relativos

\footnotetext{
19 16.1.1 OnlyFans and all of its services and features are provided without warranties of any kind, express or implied. To the fullest extent permitted by law, FIL disclaim any and all warranties, express or implied, with respect to OnlyFans and all of its services and features, including, and without limitation, implied warranties of merchantability and fitness for a particular purpose. FIL does not warrant or guarantee the accuracy, usefulness, completeness or reliability of OnlyFans, or the results of your use of OnlyFans. FIL disclaim all liability and responsibility arising from any reliance placed on such materials by you or any other visitor to the Website, or by anyone who may be informed of any of its contents. FIL also do not warrant or guarantee that OnlyFans and all of its services and features will be available at any particular time or location; that OnlyFans and all of its services and features will be secure, uninterrupted, and error-free; that any defect or error will be corrected; or that OnlyFans and all of its services and features will be free of viruses and other harmful components. You are responsible for implementing sufficient procedures and checkpoints to satisfy your particular requirements for antivirus protection and accuracy of data input and output, and for maintaining a means external to the Website for any reconstruction of any lost data. To the fullest extent provided by law, FIL will not be liable for any loss or damage caused by a distributed denial-of-service attack, viruses, or other technologically harmful material that may infect your computer equipment, computer programs, data, or other proprietary material due to your use of the Website or any services or items obtained through the Website or to your downloading of any material posted on it, or on any website linked to it. Your use of OnlyFans and its services and features will be solely and entirely at your own risk. The foregoing does not affect any warranties that cannot be excluded or limited under applicable law. Disponível em: https://koboguide. com/onlyfans-refund-tips/.

2016.1 .4 in no event shall FIL total and aggregate liability to you and/or others for any and all claims arising out of or related to your use of (or your inability to use) OnlyFans or any of its services or features, exceed one hundred pounds sterling (£100.00). This does not affect any liability that cannot be excluded or limited under applicable law. Disponível em: https://koboguide.com/onlyfans-refund-tips/.
}

2116.2 Because some jurisdictions do not allow the exclusion or limitation of liability for consequential or incidental damages or total liability, the above limitation may not apply to you. In such case, our total and aggregate liability to you arising out of or related to your use of (or your inability to use) OnlyFans or any of its services or features shall be limited to the maximum extent permitted by law or, if no amount is specified, one hundred pounds sterling (£100.00) . Disponível em: https://koboguide.com/onlyfans-refund-tips/.

22 Art. 14. O fornecedor de serviços responde, independentemente da existência de culpa, pela reparação dos danos causados aos consumidores por defeitos relativos à prestação dos serviços, bem como por informações insuficientes ou inadequadas sobre sua fruição e riscos. (BRASIL, 1990).

23 Art. 20. O fornecedor de serviços responde pelos vícios de qualidade que os tornem impróprios ao consumo ou lhes diminuam o valor, assim como por aqueles decorrentes da disparidade com as indicações constantes da oferta ou mensagem publicitária, podendo o consumidor exigir, alternativamente e à sua escolha: [...]. (BRASIL, 1990). 
à prestação dos serviços, desde que sejam defeitos restritos à natureza da atividade da plataforma, bem como por informações insuficientes ou inadequadas sobre sua fruição e riscos (artigo 14 do Código). Por exemplo, falha de segurança da plataforma que deixa escapar da rede social foto com conteúdo de "nudez", vídeo sensual e/ou dados cadastrais que deveriam ser mantidos na rede fechada, causando prejuízo à moral do usuário.

Observa-se, porém, que o fornecedor não será responsável se provar causa excludente da responsabilidade, fulcro no artigo 14, parágrafo $3^{024}$, do referido diploma legal. Apesar disto, o artigo $19^{25}$ da Lei $n^{0} 12.965 / 2014$ estipula que o provedor de aplicações de internet somente poderá ser responsabilizado civilmente por danos decorrentes de conteúdo (foto, vídeo, áudio, textos ou mensagens) gerado por terceiros (usuários da plataforma) se, após ordem judicial específica, não tomar as providências para, no âmbito e nos limites técnicos do seu serviço e dentro do prazo assinalado, tornar indisponível o conteúdo apontado como infringente, ressalvadas as disposições legais em contrário.

Feitas tais ponderações, depreende-se que o artigo 19 do Marco Civil da Internet conflita, em tese, com o artigo $6^{\circ}$, inciso VIII ${ }^{26}$, do Código Consumerista que trata dos direitos básicos do consumidor, logo, deveria prevalecer a lei especial (consumidor), em razão da sua força normativa constitucional (artigo $5^{\circ}$, XXXII $^{27}$, da Constituição Federal). Igualmente em relação ao artigo $21^{28}$ da Lei $\mathrm{n}^{\mathrm{o}} 12.965 / 2014$ e o artigo $7^{\circ}$, parágrafo único ${ }^{29}$, da Lei $\mathrm{n}^{\circ}$ 8.078/1990. Porém, nestes casos, a plataforma só responderá solidariamente após a notificação judicial que ordena a retirada do conteúdo da internet (ANDRADE; MASSON; ANDRADE, 2018).

Em outro patamar, a responsabilidade pelo vício do serviço decorre dos vícios de qualidade ou quantidade (por analogia) que tornem os serviços impróprios ao consumo, assim como por aqueles decorrentes da disparidade com as indicações constantes da oferta ou mensagem publicitária (artigo 20 do Código). Ainda, o artigo $23^{30}$ da Lei consumerista diz que a ignorância do fornecedor sobre os vícios de qualidade por inadequação dos serviços não o exime de responsabilidade. A

título de exemplo, o usuário adere a plataforma da rede social pelo pagamento mensal de 10 (dez) dólares para acesso a determinados conteúdos de Usuários Criadores e Interação

de Fãs, porém não lhe são fornecidos os acessos contratados e nem restituído o valor pago,

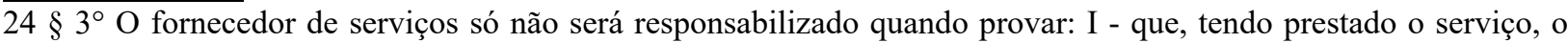
defeito inexiste; II - a culpa exclusiva do consumidor ou de terceiro. (BRASIL, 1990).

25 Art. 19. Com o intuito de assegurar a liberdade de expressão e impedir a censura, o provedor de aplicações de internet somente poderá ser responsabilizado civilmente por danos decorrentes de conteúdo gerado por terceiros se, após ordem judicial específica, não tomar as providências para, no âmbito e nos limites técnicos do seu serviço e dentro do prazo assinalado, tornar indisponível o conteúdo apontado como infringente, ressalvadas as disposições legais em contrário. (BRASIL, 2014).

26 VIII - a facilitação da defesa de seus direitos, inclusive com a inversão do ônus da prova, a seu favor, no processo civil, quando, a critério do juiz, for verossímil a alegação ou quando for ele hipossuficiente, segundo as regras ordinárias de experiências; (BRASIL, 1990)

27 XXXII - o Estado promoverá, na forma da lei, a defesa do consumidor; (BRASIL, 1988)

28 Art. 21. O provedor de aplicações de internet que disponibilize conteúdo gerado por terceiros será responsabilizado subsidiariamente pela violação da intimidade decorrente da divulgação, sem autorização de seus participantes, de imagens, de vídeos ou de outros materiais contendo cenas de nudez ou de atos sexuais de caráter privado quando, após o recebimento de notificação pelo participante ou seu representante legal, deixar de promover, de forma diligente, no âmbito e nos limites técnicos do seu serviço, a indisponibilização desse conteúdo.

29 Parágrafo único. Tendo mais de um autor a ofensa, todos responderão solidariamente pela reparação dos danos previstos nas normas de consumo. (BRASIL, 1994)

30 Art. 23. A ignorância do fornecedor sobre os vícios de qualidade por inadequação dos produtos e serviços não o exime de responsabilidade. (BRASIL, 1990) 
gerando vício à incolumidade econômica do usuário, como aconteceu no caso análogo da atriz da Disney Channel Bella Thorne que será melhor ilustrado abaixo.

Vê-se, então, que as cláusulas de não indenizar ou as que excluam ou atenuem a responsabilidade da OnlyFans previstas no contrato de adesão são tidas como nulas para o ordenamento jurídico brasileiro frente à vulnerabilidade técnica, jurídica, fática ou econômica do consumidor. Apesar de tais cláusulas estarem previstas, a rede social fornecedora de conteúdo poderá ser responsabilizada se constatada a sua responsabilidade no caso concreto, nos termos do Código de Defesa do Consumidor.

Ainda no que tange às cláusula abusivas, o Código Consumerista, no artigo 51, incisos $\mathrm{IX}^{31}, \mathrm{X}^{32}, \mathrm{XI}^{33}$ e XIII ${ }^{34}$, atesta que é abusiva a cláusula que: deixar ao fornecedor a opção de concluir ou não o contrato, embora obrigando o consumidor; permite ao fornecedor, direta ou indiretamente, variar o preço de maneira unilateral; autorize o fornecedor a cancelar o contrato unilateralmente, sem que igual direito seja conferido ao consumidor; e autorize o fornecedor a modificar unilateralmente o conteúdo ou a qualidade do contrato, após sua celebração.

Pois bem. Caso interessante ocorreu com a atriz da Disney Channel, a Bella Thorne. Segundo a reportagem do site da Folha (FOLHAPRESS, 2020), publicada em 30 de agosto de 2020, a atriz, criadora de conteúdo virtual na rede social OnlyFans, ofereceu aos usuários-fãs, através de mensagens, um conteúdo de imagens em que apareceria sem roupa por um valor de duzentos dólares, faturando, assim, mais de um milhão de dólar em um dia na plataforma. Porém, Bella não enviou tais fotos com conteúdo erótico para os usuários, enviando apenas fotos de roupa íntima (lingerie). Em consequência, a atriz foi acusada de "calote". Com isso, a rede social, conhecida por não proibir conteúdo de "nudez" e por ter conteúdos exclusivos de imagens eróticas, recebeu inúmeras reclamações de Usuários Fãs.

Em razão disto, a empresa decidiu, unilateralmente, limitar o valor do serviço de conteúdo oferecido pela atriz em cinquenta dólares e das gorjetas em, no máximo, cem dólares, bem como alterar o tempo para o pagamento ser efetivado na conta da Usuária Criadora, passando de sete dias para trinta dias. Todavia, observa-se que, devido ao fato ocorrido com um Usuário Criador, a plataforma alterou, unilateralmente, no meio da "partida", as regras do "jogo" para todos os Usuários Criadores, causando críticas e insatisfação na mídia social. A justificativa da OnlyFans restringiu-se a evitar gastos excessivos e permitir que os usuários continuem usando a rede social com segurança. Entretanto, na prática, a plataforma atuou, em tese, de forma abusiva quando alterou unilateralmente o contrato e o preço pelo conteúdo oferecido no meio do jogo/ contrato, violando o disposto no Código do Consumidor. Isso porque o preço deve ser pactuado no momento da celebração do contrato e não alterado a posteriori ao livre arbítrio das partes.

Para mais, destaca-se que o Código não veda apenas a alteração unilateral direta do

31 IX - deixem ao fornecedor a opção de concluir ou não o contrato, embora obrigando o consumidor (BRASIL, 1990);

32 X - permitam ao fornecedor, direta ou indiretamente, variação do preço de maneira unilateral (BRASIL, 1990);

33 XI - autorizem o fornecedor a cancelar o contrato unilateralmente, sem que igual direito seja conferido ao consumidor (BRASIL, 1990);

34 XIII - autorizem o fornecedor a modificar unilateralmente o conteúdo ou a qualidade do contrato, após sua celebração (BRASIL, 1990); 
preço, mas de qualquer fator que, estando ao arbítrio de uma única parte, tenha o poder de alterar indiretamente a cláusula-preço (ANDRADE; MASSON; ANDRADE, 2018). No caso, o Usuário Criador adere as cláusulas do contrato de adesão, concordando com aquilo que está exposto naquela ocasião, não podendo o conteúdo, o preço e/ou a qualidade ser modificados a posteriori de forma unilateral pela mera vontade do fornecedor. Isto significa, estabelecidas as "regras do jogo", o objeto, o preço, a forma de pagamento e as condições de fornecimento, tem-se perfeito e acabado, fazendo-se leis entre as partes (ANDRADE; MASSON; ANDRADE, 2018). Melhor dizendo, portanto, toda e qualquer alteração contratual, superveniente à conclusão do contrato de consumo, deve ser levada a cabo por tratativas bilaterais das partes, uma vez que o Código Consumerista visa preservar o equilíbrio negocial entre a plataforma-fornecedora de conteúdo e o usuário-consumidor, nos termos do artigo $4^{\circ}$, inciso III ${ }^{35}$, da Lei $n^{\circ} 8.078 / 1990$, caso contrário, a cláusula será nula de pleno direito.

Para culminar, a plataforma consagra uma cláusula que permite a alteração de qualquer termo contratual, de forma unilateral e a qualquer tempo. A cláusula $1.5^{36}$ informa que a FIL se reserva a fazer alterações aos termos a qualquer momento e a seu critério exclusivo. Nota-se que, na perspectiva do Código Consumerista, artigo 51, inciso XIII, a cláusula que prevê a alteração unilateral pela plataforma de qualquer termo contratual e a qualquer momento sem respeitar os limites legais é abusiva, sendo nula de pleno direito.

Regressando ao caso da atriz Bella Thorne, questiona-se: a oferta vincula o fornecedor de conteúdo? Consoante a inteligência do artigo $30^{37}$ do Código de Defesa do Consumidor toda informação ou publicidade, suficientemente precisa, veiculada por qualquer meio com relação a serviços oferecidos obriga o fornecedor que a fizer veicular e integra o contrato que vier a ser celebrado.

Logo após, o artigo $35^{38}$ do mesmo diploma legal assegura alternativas ao consumidor (por exemplo: obrigação de fazer, aceitar outro serviço equivalente ou rescindir o contrato) se o fornecedor de serviços recusar cumprimento à oferta. Acrescenta-se a isso que o princípio da vinculação da oferta, corolário do princípio da boa-fé objetiva, considera que a oferta cria a obrigação pré-contratual para que não se frustre a legítima expectativa criada no consumidor, ou

35 Art. $4^{\circ}$ A Política Nacional das Relações de Consumo tem por objetivo o atendimento das necessidades dos consumidores, o respeito à sua dignidade, saúde e segurança, a proteção de seus interesses econômicos, a melhoria da sua qualidade de vida, bem como a transparência e harmonia das relações de consumo, atendidos os seguintes princípios: [...] III - harmonização dos interesses dos participantes das relações de consumo e compatibilização da proteção do consumidor com a necessidade de desenvolvimento econômico e tecnológico, de modo a viabilizar os princípios nos quais se funda a ordem econômica (art. 170, da Constituição Federal), sempre com base na boa-fé e equilíbrio nas relações entre consumidores e fornecedores (BRASIL, 1990).

361.5 FIL reserves the right to make changes to these Terms at any time and at FIL's sole discretion. All changes are effective immediately from the time FIL posts them, and apply to all access to and use of the Website thereafter. By continuing to use OnlyFans, you agree to the Terms as modified or as they currently appear. You are expected to check this page from time to time so you are aware of any changes, as they are binding on you. Disponível em: https://koboguide.com/onlyfans-refund-tips/.

37 Art. 30. Toda informação ou publicidade, suficientemente precisa, veiculada por qualquer forma ou meio de comunicação com relação a produtos e serviços oferecidos ou apresentados, obriga o fornecedor que a fizer veicular ou dela se utilizar e integra o contrato que vier a ser celebrado (BRASIL, 1990).

38 Art. 35. Se o fornecedor de produtos ou serviços recusar cumprimento à oferta, apresentação ou publicidade, o consumidor poderá, alternativamente e à sua livre escolha: I - exigir o cumprimento forçado da obrigação, nos termos da oferta, apresentação ou publicidade; II - aceitar outro produto ou prestação de serviço equivalente; III rescindir o contrato, com direito à restituição de quantia eventualmente antecipada, monetariamente atualizada, e a perdas e danos(BRASIL, 1990). 
seja, a "promessa é dívida" (ANDRADE; MASSON; ANDRADE, 2018).

Acredita-se, assim, que por causa da oferta de imagens "sem roupa" da atriz, por meio de mensagens instantâneas, os Usuários Fãs adquiram, mediante pagamento, o serviço de fotos e/ou vídeos desta Usuária Criadora. Isto é, só se tornaram fãs da Criadora pela promessa de tais imagens, porém, suas expectativas restaram frustradas.

Dado isso, indaga-se: a plataforma poderia ser acionada judicialmente por não ter fornecido o conteúdo ofertado pela atriz Bella Thorne? E a Usuária Criadora, também poderia? E, seria possível um reembolso dos valores pagos pela oferta veiculada e/ou a obrigação de fazer? A plataforma poderia ser acionada judicialmente por não ter fornecido o conteúdo ofertado pela atriz, pois, como dito acima e previsão legal no Código Consumerista, a oferta vincula o fornecedor. Mais, a Usuária Criadora também poderia ser acionada, em tese, conforme os comentários feitos anteriormente em relação à responsabilidade civil, dado que, apesar de a rede social responder objetivamente pela oferta, poderia a OnlyFans, ingressar com ação de regresso em face da atriz criadora de conteúdo para apurar a devida responsabilidade, se os usuários afetados não o fizerem.

Quanto ao reembolso/restituição dos valores, seria possível, visto que o inciso III $^{39}$, do artigo 35, do Código dispõe que o consumidor, ora Usuário, pode rescindir o contrato, com direito à restituição de quantia eventualmente antecipada, monetariamente atualizada, possuindo, ainda, direito a perdas e danos, a depender dos fatos do caso concreto. No mais, segundo o inciso $\mathrm{II}^{40}$, do artigo 35, do Código mencionado, o Usuário pode escolher aceitar prestação de serviço equivalente, como fotos sensuais de roupa íntima ao invés da prometida foto de "nudez". Todavia, no que corresponde à obrigação de fazer, apesar de o artigo 35 , inciso I ${ }^{41}$, do Código Consumerista assegurar que o consumidor pode exigir o cumprimento forçado da obrigação, nos termos da oferta, no caso em tela, por se tratar de conteúdo de "nudez" não seria a opção mais aceitável, uma vez que a finalidade da teoria prevista no Código poderia ser desvirtuada na prática, inclusive gerar ilícitos induzidos (SOLARI MERLO, 2021).

Por último, mas não menos importante, partindo da compreensão do artigo 51, inciso $\mathrm{XI}^{42}$, do Código advém que a cláusula é abusiva e nula de pleno quando autoriza o fornecedor a cancelar o contrato unilateralmente, sem que igual direito seja conferido ao consumidor, pois o objetivo aqui é enaltecer os princípios da boa-fé, confiança e do equilíbrio contratual. No entanto, apesar de a OnlyFans permitir que o usuário se desligue a qualquer tempo da plataforma, não sendo reembolsados os valores já pagos ou contratados, contém cláusulas ${ }^{43}$ que permitem o cancelamento do contrato, a exclusão ou suspensão do usuário, e outras ações, inclusive sem informação prévia.

Resumidamente observa-se das cláusulas que: (I) a FIL se reserva no direito de, a 39 III - rescindir o contrato, com direito à restituição de quantia eventualmente antecipada, monetariamente atualizada, e a perdas e danos (BRASIL, 1990).

40 II - aceitar outro produto ou prestação de serviço equivalente (BRASIL, 1990);

41 I - exigir o cumprimento forçado da obrigação, nos termos da oferta, apresentação ou publicidade;

42 XI - autorizem o fornecedor a cancelar o contrato unilateralmente, sem que igual direito seja conferido ao consumidor;

43 Disponível em: https://koboguide.com/onlyfans-refund-tips/. 
qualquer momento e sem prévio aviso, modificar, suspender ou encerrar a rede social ou qualquer serviço dela; ou de restringir, limitar, suspender ou encerrar o acesso do usuário a plataforma; ou, ainda, excluir conteúdo que o Usuário Criador postar $\left(1.9^{44}, 1.9 .1^{45}, 1.9 .2^{46}, 1.9 .3^{47}\right)$; e (II) a FIL se reserva no direito de desativar, a qualquer momento e a seu critério exclusivo, nome, senha ou outro identificador de usuário $\left(3.8^{48}\right)$.

Daí depreende-se, por fim, que há violação, ainda que indireta, dos princípios da informação, da boa-fé objetiva e da confiança, visto que o usuário do serviço de conteúdo fica em constante alerta quanto às expectativas em relação ao contrato com a plataforma.

Portanto, ante as considerações, constata-se a necessidade de o Estado intervir no mercado para regular e fiscalizar as normas inerentes à relação de consumo para que haja mais eficiência e equilíbrio contratual, evitando-se, assim, cláusulas contratuais abusivas de forma excessiva, contudo, ressalta-se que a excessiva intervenção do Estado (em todos os níveis) na seara contratual pode tanto trazer instabilidade no ambiente econômico, acarretando mais custos de transação às partes como gerar externalidades negativas (TIMM, 2009), por isso a importância de realizar a análise jurídica das cláusulas da rede social no panorama da legislação brasileira de proteção ao consumidor vulnerável, em especial, tecnicamente.

\section{CONCLUSÃO}

Após as análises fundamentais para a construção deste artigo é viável concluir que a rede social OnlyFans possui estrito campo de incidência do Código de Defesa do Consumidor, uma vez que consagra os elementos subjetivos da relação de consumo, isto é, o Usuário como consumidor em sentido estrito ou equiparado, a depender do caso concreto e a plataforma (incluindo o Usuário Criador) como fornecedora de serviço, assim como a empresa oferece no mercado de consumo o serviço de conteúdo virtual de fotos, vídeos e/ou áudios com ou sem mensagens ou textos, mediante remuneração direta ou indireta.

Além disso, viu-se a importância do tema diante dos possíveis reflexos jurídicos no ordenamento jurídico brasileiro, tendo em vista as repercussões múltiplas que podem advir tanto pela falta de informação ou de conteúdo para o consumidor quanto pelo fornecimento de conteúdo com vício ou fato do serviço.

Por último, constatou-se a relevância de o consumidor virtual da OnlyFans ter ciência de algumas cláusulas contratuais consideradas abusivas perante o Código de Defesa do Consumidor, além de conhecer as consequências jurídicas no âmbito da responsabilidade civil, minimizando, 441.9 FIL reserves the right at any time and without notice to:

45 1.9.1 modify, suspend or terminate OnlyFans or any portion thereof;

46 1.9.2 restrict, limit, suspend or terminate your access to OnlyFans or any portion thereof

47 1.9.3 delete any content you post on OnlyFans as a Creator if in FIL's reasonable opinion it does not comply with these Terms and/or any applicable law; Disponível em: https://koboguide.com/onlyfans-refund-tips/.

483.8 FIL reserves the right to disable any user name, password, or other identifier, whether chosen by you or provided by FIL, at any time and at FIL's sole discretion for any or no reason, including if, in FIL opinion, you have violated any provision of the Terms; Disponível em: https://koboguide.com/onlyfans-refund-tips/. 
assim, se é que é possível, eventuais falhas de mercado ante as práticas abusivas, posto que estas são nulas de pleno direito à luz do Código Consumerista.

Conclui-se, portanto, que a rede social OnlyFans chegou para inovar as espécies de serviços fornecidos no mercado de consumo virtual, gerando inúmeras curiosidades e reflexos jurídicos frente ao Código de Defesa do Consumidor, em especial no que se refere as cláusulas contratuais abusivas.

\section{REFERÊNCIAS}

ANDRADE, Adriano; MASSON, Cleber; ANDRADE, Landolfo. Interesses Difusos e Coletivos. 8. ed. São Paulo: Método, 2018.

ANDRADE, Tadeu Luciano Siqueira. A vulnerabilidade jurislinguística nas relações contratuais: uma análise semântico-pragmática à luz do direito do consumidor. Revista Direitos Fundamentais e Alteridade, Salvador, v. 4, n. 2, p. 65-82, jul./dez., 2020. Disponível em: https://periodicos.ucsal.br/index.php/direitosfundamentaisealteridade/article/view/782/583. Acesso em: 29 abr. 2021.

BALDUÍNO JÚNIOR, Gean Carlos; SANTIAGO, Mariana Ribeiro. Consumo e mercado: alternativas à tutela do consumidor e à defesa da concorrência na sociedade líquida. Revista Direitos Sociais e Políticas Públicas, Bebedouro, v. 9, n. 1, jan./abr. 2021. Disponível em: https://www.unifafibe.com.br/revista/index.php/direitos-sociais-politicas-pub/article/view/983/ pdf. Acesso em: 29 abr. 2021.

BRASIL. Lei $\mathbf{n}^{\mathbf{0}} \mathbf{8 . 0 7 8}$, de 11 de setembro de 1990. Dispõe sobre a proteção do consumidor e dá outras providências. Brasília: Senado, 1990. Disponível em: http://www.planalto.gov.br/ ccivil_03/Leis/L8078.htm. Acesso em: 06 dez. 2020.

BRASIL. [Constituição (1988)]. Constituição da República Federativa do Brasil. Brasília: Presidência da República, 1988. Disponível em: http://www.planalto.gov.br. Acesso em: 06 dez. 2020.

BRASIL. Lei $\mathbf{n}^{\mathbf{0}} \mathbf{1 2 . 9 6 5}$, de 23 de abril de 2014. Estabelece princípios, garantias, direitos e deveres para o uso da Internet no Brasil. Brasília: Senado, 2014. Disponível em: http://www. planalto.gov.br/. Acesso em: 06 dez. 2020.

GANEM, Pedro. Detentos vendem conteúdo erótico em plataforma digital de dentro do presídio. Canal de Ciências Criminais, abr., 2021. Disponível em: https:/canalcienciascriminais.com.br/ detentos-vendem-conteudo-erotico-em-plataforma-digital/. Acesso em 29 abr. 2021.

CZELUSNIAK, Vivian Amaro. Uma análise socioeconômica sobre a aplicação do princípio da dignidade humana no Direito do Consumidor. Revista Direito e Desenvolvimento. vol. 9, n. 2, p. 319-334, ago./dez. 2018. Disponível em: https://periodicos.unipe.br/index.php/ direitoedesenvolvimento/article/view/598/569. Acesso em: 29 abr. 2021. 
FOLHAPRESS. Bella Thorne dá calote em usuários do OnlyFans e revolta produtores de conteúdo erótico. Folha de Pernambuco, 30 ago. 2020. Disponível em: https://www.folhape. com.br/cultura/bella-thorne-da-calote-em-usuarios-do-onlyfans-e-revolta-produtores-de/152931/. Acesso em: 10 dez. 2020.

\section{LAHER, Raissa Salim Ebrahim. A influência do instagram no comportamento do}

consumidor online. 2019. 105 f. Dissertação (Mestrado em Ciências da Comunicação) - Lisboa, Universidade Católica Portuguesa, 2019.

MONTARDO, Sandra Portella; ARAÚJO, Willian. Performance e práticas de consumo online: ciberativismo em sites de redes sociais. Revista FAMECOS: mídia, cultura e tecnologia, Lisboa, v. 20, n. 2, p. 472-497, maio/ago. 2013.

NASCIMENTO, Carlo Bruno Lopes do. A problemática da informação imperfeita nas relações de consumo e a necessidade de proteção do vulnerável. Revista do Instituto do Direito Brasileiro, n. 2, p. 381-408, Lisboa, 2015. Disponível em: https://www.cidp.pt/publicacoes/ revistas/rjlb/2015/2/2015_02_0381_0408.pdf. Acesso em: 29 abr. 2021.

ONLYFANS. Disponível em: https://onlyfans.com/terms. Acesso em: 10 dez. 2020a.

ONLYFANS. Disponível em: https://onlyfans.com/terms/user-content. Acesso em: 29 nov. 2020 b.

ROSSIGNOLI, Marisa; ALMEIDA, Patrícia Silva de. Governamentabilidade neoliberal: reflexões sobre o crescimento econômico e o crescimento inclusivo. Revista de Direito Econômico e Socioambiental. v. 9, n. 3, p. 219-242, set./dez. 2018. Disponível em: https:// periodicos.pucpr.br/index.php/direitoeconomico/article/view/23440/23499. Acesso em: $29 \mathrm{abr}$. 2021.

SILVESTRINI, João Pedro; GERAIGE NETO, Zaiden; VILELA, Thiago Ribeiro Franco. A contribuição do Código de Defesa do Consumidor na tutela de interesses individuais e coletivos. Revista Direito e Justiça, Santo Angelo, v. 19, n. 34, maio/ago. 2019. Disponível em: http:// srvapp2s.santoangelo.uri.br/seer/index.php/direito_e_justica/article/view/2869/1803. Acesso em: 29 abr. 2021.

SOLARI MERLO, Mariana Noelia. Medidas de autoprotección en redes sociales. Análisis de los hábitos de los usuarios de Facebook, Instagram y Twitter. Archivos de Criminología, Seguridad Privada y Criminalística, v. 8, v. 17, p. 91-117, ago./dec. 2021. Disponível em: https://zenodo.org/record/4568523\#.YIsWb7VKjIV. Acesso em: 29 abr. 2021.

TARTUCE, Flávio; NEVES, Daniel Amorim Assumpção. Manual de Direito do Consumidor: direito material e processual. 9. ed. São Paulo: Método, 2020.

TIMM, Luciano Benetti. Ainda sobre a função social do Direito Contratual no Código Civil brasileiro: justiça distributiva versus eficiência econômica. Revista da AMDE, Belo Horizonte, v. 2, 2009. Disponível em: http://www.revista.amde.org.br/index.php/ramde/article/view/26/24. Acesso em: 29 abr. 2021. 
Como citar: VITA, Jonathan Barros; DE OLIVEIRA, Bruno Bastos; COSTA, Ana Carolina Pazin. Aspectos jurídicos relacionados à rede social onlyfans: uma abordagem na perspectiva das relações de consumo. Scientia luris, Londrina, v. 25, n. 3, p. 141-158, nov. 2021. DOI: 10.5433/21788189.2021v25n3p141. ISSN: 2178-8189.

Recebido em 2021-05-03

Aprovado em 2021-09-11 